\title{
ERGOLOGIA E AVIAÇÃO CIVIL: perspectivas de pesquisa
}

\author{
ERGOLOGY AND CIVIL AVIATION: research perspectives \\ ERGOLOGÍA Y AVIACIÓN CIVIL: perspectivas de investigación
}

\begin{abstract}
Mayara Vieira Henriques ${ }^{\mathrm{i}}$
Alexandre de Carvalho Castro ${ }^{\text {ii }}$

Resumo: Na Aviação Civil, os Fatores Humanos são os maiores ativos e a maior fonte de risco na execução da atividade diante da automação presente no setor. O objetivo do estudo é apresentar a significância dos estudos sobre Fatores Humanos na aviação a partir da abordagem ergológica. A metodologia consiste na realização de um levantamento bibliográfico utilizando como base de dados os principais autores da Ergologia, revistas científicas e instituições da Aviação Civil. O resultado evidencia a pertinência de se compreender a subjetividade das atividades do setor, cujo desempenho humano é essencial para a garantia da segurança operacional.
\end{abstract}

\begin{abstract}
In Civil Aviation, Human Factors are the biggest assets and the biggest source of risk in the execution of the activity due to the automation present in the sector. The aim of the study is to present the significance of studies on Human Factors in aviation from the ergological approach. The methodology consists of conducting a bibliographic survey using the main authors of Ergology, scientific journals and institutions of Civil Aviation as a database. The result highlights the pertinence of understanding the subjectivity of the sector's activities, whose human performance is essential to guarantee operational safety.
\end{abstract}

Resumen: En la aviación civil, los factores humanos son los mayores activos y la mayor fuente de riesgo en la ejecución de la actividad debido a la automatización presente en el sector. El objetivo del estudio es presentar la importancia de los estudios sobre factores humanos en la aviación desde el enfoque ergológico. La metodología consiste en realizar una encuesta bibliográfica utilizando como base de datos los principales autores de Ergología, revistas científicas e instituciones de Aviación Civil. El resultado destaca la pertinencia de comprender la subjetividad de las actividades del sector, cuyo desempeño humano es esencial para garantizar la seguridad operacional.

Palavras-chave: Aviação Civil; Ergologia; Fatores Humanos.

Keywords: Civil Aviation; Ergology; Human Factors.

Palabras claves: Aviación civil; Ergología; Factores humanos. 


\section{INTRODUÇÃO}

A aplicação do entendimento sobre os Fatores Humanos foi praticada na aviação por mais de 50 anos antes de receber tal título (ADAMS, 2006). Contudo, o reconhecimento de que a educação básica em Fatores Humanos era necessária para toda a indústria aeronáutica pode ser vista como um marco histórico do campo de pesquisa (HAWKINS, 2016), dado que o Fator Humano é uma das variáveis mais sensíveis do sistema, o que é comprovado pelas estatísticas de ocorrências aeronáuticas, onde, apenas no Brasil, o Fator Humano - em sua condição biológica - é contribuinte em 34\% dos casos das ocorrências aéreas na última década (CENIPA, 2019).

À vista disso, os Fatores Humanos receberam uma maior aceitação no setor como parte essencial do ciclo de produção e serviços do setor, resultado do papel crítico que os indivíduos, especialmente os pilotos, desempenham nesses sistemas homem-máquinaambiente, os problemas e desafios singulares que esses mecanismos representam na percepção, na fisiologia e cognição humana, e as possíveis graves consequências do erro humano nesses arranjos organizacionais (MAURINO, 2010).

Até o momento, porém, as pesquisas sobre o Fator Humano no sistema aeronáutico têm sido orientadas predominantemente para a garantia da segurança (HARRIS, 2011), requisito básico de qualidade do setor. Wise e Hopkin (2009) evidenciam a facilitação da segurança e eficiência do ambiente de trabalho como sua aplicação mais importante no domínio da aviação, viabilizado através da incorporação de paradigmas conhecidos sobre os seres humanos e sua relação como operador de máquinas e sistemas.

Dejours (2005) ressalta a dicotomia existente nas perspectivas dos estudos do Fator Humano. Compreende, em um primeiro momento, o Fator Humano como um ponto de falha, cuja orientação normativa é baseada no controle, monitoramento e segurança. Em oposição, a segunda abordagem considera o Fator Humano como recurso, destacando a complexidade das relações do indivíduo com a organização.

É útil compreender o Fator Humano como um jogo de interações do coletivo de trabalho, cujas condutas são mutáveis e as atividades exigem além das habilidades técnicas, englobando o conhecimento tácito, astúcia e criatividade (DEJOURS, 2005). Nessa conjuntura, a perspectiva da ergologia possui maior aderência com a contribuição dos Fatores Humanos na aviação.

Em tal caso, a conscientização da pluralidade característica dos estudos sobre Fatores Humanos, por parte de todas as instituições que compreendem o setor, é determinante para prescrição de métodos preventivos que corroborem com a segurança operacional e reduza 
os índices de ocorrências aeronáuticas - todo incidente ou acidente envolvendo aeronaves resultantes da contribuição humana.

À vista disso, o objetivo deste trabalho é apresentar a pertinência dos estudos sobre Fatores Humanos na Aviação Civil a partir da abordagem ergológica, destacando a carência de uma perspectiva subjetiva da natureza humana diante da racionalidade inerente ao setor.

\section{MÉTODO}

O método abordado no estudo se orienta a partir do questionamento sobre a relevância de compreender os Fatores Humanos nas operações da Aviação Civil através da perspectiva ergológica, com foco na garantia da segurança operacional e nos aspectos psicológicos e fisiológicos do indivíduo que gerencia os recursos e executa atividades com risco potencial a qualidade do serviço.

O procedimento de investigação se estabeleceu a partir da escolha em utilizar exclusivamente bases de dados online. Foi realizado o levantamento bibliográfico utilizando como base de dados os principais autores da Ergologia, assim como as principais revistas científicas e instituições da Aviação Civil.

A pesquisa exploratória revelou a existência de uma lacuna na literatura que compreenda o estudo da Ergologia aplicada a Aviação Civil. Destaca-se a predominância de estudos com caráter tecnológico nas pesquisas centradas no indivíduo, onde a tecnologia é vista como solução racional, objetiva e rápida para identificação, controle e monitoramento dos aspectos psicossociais e fisiológicos que acometem o Fator Humano durante as operações aéreas.

\section{DISCUSSÃO}

O elemento humano é a parte mais flexível no segmento da aviação, nesse sentido, torna-se a parte mais vulnerável às influências que podem afetar seu desempenho (BESSI, 2018). É importante, no âmbito dos Fatores Humanos, respeitar a necessidade de haver um equilíbrio entre segurança e eficiência e que, ao tentar maximizar a segurança com mais prescrições, a eficiência do sistema não seja comprometida na medida em que não atende completamente todas as interfaces (MORIARTY, 2015). Kanki et al (2010) ressaltam que um ser humano no ato de executar uma atividade, operar equipamentos, não importa quão bem selecionado, treinado ou aplicado, o indivíduo está sujeito a limitações que impactam no desempenho do sistema. 
A abordagem ergológica, sem objetivar modelos de análise única, concebe o trabalho como um combinado de aspectos técnicos com ação humana, numa relação de abundante singularidade frente às demandas do mundo laboral (HOLZ, 2013). SCHWARTZ (2016) resume a abordagem ergológica como:

\begin{abstract}
...um mundo saturado de normas antecedentes em todo agir, como o é o mundo humano, a abordagem ergológica concebe a atividade como uma trama de renegociações permanentes dessas normas. Renegociações que visam, para todo indivíduo e coletividade, uma possibilidade de viver com saúde cada encontro com o momento presente, momento sempre misto de sedimentações históricas e de circunstâncias inéditas "Texto Traduzido" (SCHWARTZ, 2016, p. 93, tradução nossa).
\end{abstract}

Isto posto, o estudo da ergologia considera o princípio de pensar e ver toda atividade como consequência de certa abordagem da atividade humana, formalização de um modo particular de produção de conhecimentos que assenta no diálogo entre os saberes elaborados pelas disciplinas acadêmicas tradicionais e os saberes que os diversos protagonistas das atividades humanas põem em prática na execução da sua atividade (DI RUZZA et al, 2018).

No domínio da Aviação Civil, os saberes acadêmicos estão atrelados à prescrição de procedimentos que são fundamentais para criação de barreiras de segurança em toda cadeia. No entanto, as atividades não se tornam imunes a certo grau de imprevisibilidade. Landman et al (2017) destaca que na prática operacional a mera formação teórica pode ser insuficiente durante um evento inesperado, sendo necessário o reenquadramento das habilidades para lidar com tais situações.

Pilotar aeronaves, por exemplo, é uma atividade que exige muito mais do que a execução automática de movimentos. Uma coordenação motora fina, tomada de decisões e resposta a estímulos ágeis são imprescindíveis durante todo processo de voo. O trabalho realizado pelos pilotos nem sempre é visto e pouco sobre ele é analisado, especialmente com o foco na natureza subjetiva do Fator Humano.

Pode-se evidenciar que grande parte da atividade é marcada por uma racionalidade que decorre das situações concretas, que pela perspectiva ergológica não poderá derivar de uma única racionalidade, seja a do profissional que elabora a prescrição, seja a do próprio trabalhador que desempenha a atividade (MOTTA, 2012).

Logo, o trabalhador não possui plena e imediata consciência da atividade realizada, sendo necessário refletir para desenvolvê-la, uma vez que estará presente uma produção não consciente e uma economia do próprio corpo (MOTTA, 2012). Nesse sentido, a ergologia emerge como uma possibilidade de reflexão sobre os saberes normatizados e a experiência 
daqueles que, de fato, vivenciam as situações reais de pilotagem e são constantemente convocados a realizarem processos de renormatizações.

\section{CONSIDERAÇÕES FINAIS}

Em sistemas complexos, como o segmento da Aviação Civil, o fomento ao estudo dos Fatores Humanos é substancial para garantia da segurança e eficiência do setor. Assim como as normativas e estratégias organizacionais são barreiras em combate à imprevisibilidade existente na atividade, seja por condições climáticas, confiabilidade dos equipamentos e a variabilidade do desempenho humano. É válido salientar que, como outros elementos da aviação, é considerável que os Fatores Humanos sejam estudados e/ou adaptados ao país de aplicação em atenção às características ambientais e culturais que são particulares em cada localidade.

A pesquisa em desenvolvimento contribui para evidenciar a relevância de compreender o papel significativo do homem na aviação civil através da perspectiva ergológica, fortalecendo o valor dos estudos sobre os Fatores Humanos, dado o momento em que a automação é considerada o principal recurso para promoção da segurança operacional. A sua ampliação trará a possibilidade de aprofundar o conhecimento sobre os aspectos psicofisiológicos que acometem o Fator Humano devido à natureza da atividade aérea, tal como perceber a dinâmica entre vida e saúde, assim como as possíveis criações e renormatizações presentes nas mais adversas situações.

O presente trabalho está sendo realizado com apoio da Coordenação de Aperfeiçoamento de Pessoal de Nível Superior Brasil (CAPES) - Código de Financiamento 001.

\section{REFERÊNCIAS}

ADAMS, D. A Layman's Introduction to Human Factors in Aircraft Accident and Incident Investigation. Australian Transport Safety Bureau. Austrália, 2006.

BESSI, P. Fator Humano Na Investigação E Prevenção De Acidentes Aeronáuticos: Estudo de Caso do Acidente com a Aeronave Pr-Som. Universidade do Sul de Santa Catarina (UNISUL). Palhoça, 2018.

CENTRO DE INVESTIGAÇÃO E PREVENÇÃO DE ACIDENTES AERONÁUTICOS (CENIPA). Painel Sipaer. Panorama dos Acidentes nos últimos 10 anos. Disponível em: <http://painelsipaer.cenipa.aer.mil.br/>. Acesso em: 07/02/2019.

DEJOURS, C. O Fator Humano. Fundação Getúlio Vargas (FGV), 2005. 
DI RUZZA, R., LACOMBLEZ, M., SANTOS, M. Ergologia, Trabalho, Desenvolvimentos. Série Trabalho e Sociedade, Belo Horizonte, 2018.

HARRIS, D. Human Performance On The Flight In Deck. Taylor \& Francis Group, 2011.

HAWKINS, H, F. Human Factors in Flight. Routledge, 2016.

HOLZ, E. B. Pesquisa Ergológica: Cientificidade, Coerência, Paradigma e Articulação Conceitual. Revista Gestão \& Conexões. Vitória (ES), v. 2, n. 1, jan./jun. 2013.

KANKI, G. B., HELMREICH, L. R., ANCA, J. Crew Resource Management. Elsevier Inc, 2010.

LANDMAN, A., GROEN, E. L., VAN PAASSEN, M. M., BRONKHORST, A. W., MULDER, M. Dealing With Unexpected Events on the Flight Deck: A Conceptual Model of Startle and Surprise. Human Factors: The Journal of the Human Factors and Ergonomics Society, 59(8), 1161-1172, 2017.

MAURINO, D. S. E. Human Factors in Aviation. Elsevier Inc, 2010.

MORIARTY, D. Pratical Human Factors for pilots. Elsevier Inc, 2015.

MOTTA, S. V. Formações Discursivas na Aviação: do Embate entre a Máquina e o Homem-Executor, ao Debate de Normas do Homem-Trabalhador. Tese de Doutorado. Universidade Federal Fluminense, Niterói, 2012.

SCHWARTZ, Y. Abordagem Ergológica e Necessidade de Interfaces Pluridisciplinares. ReVEL, edição especial n. 11, 2016. [www.revel.inf.br].

WISE, A. J, HOPKIN, D. V. Human Factors in Certification. Taylor \& Francis e-Library, 2009.

\footnotetext{
i Mestranda do Programa de Pós-graduação em Engenharia de Produção e Sistemas do Centro Federal de Educação Tecnológica Celso Suckow da Fonseca - CEFET/RJ, mayaravhenriques@gmail.com.

ii Docente do Programa de Pós-graduação em Engenharia de Produção e Sistemas do Centro Federal de Educação Tecnológica Celso Suckow da Fonseca - CEFET/RJ, o.aken@uol.com.br.
} 